
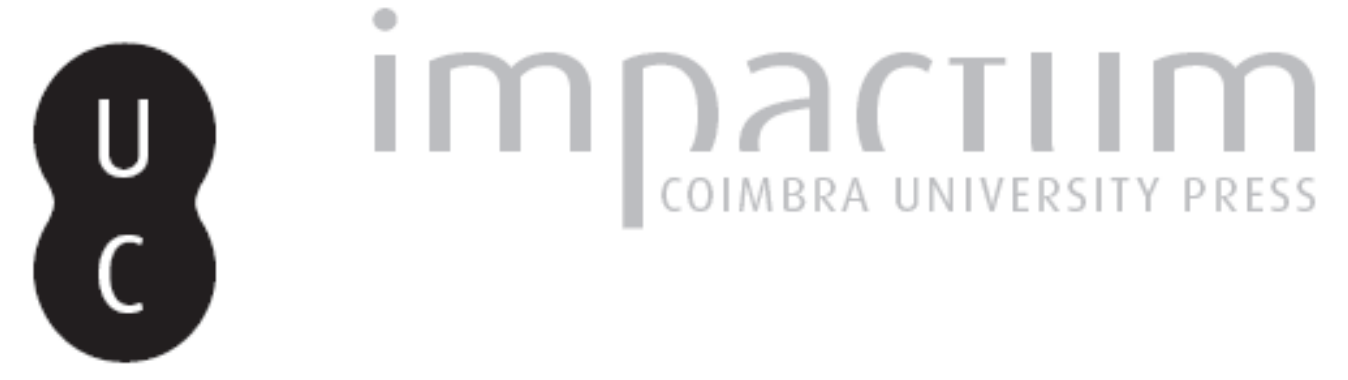

\title{
"Incapacidade total para o trabalho": proposta de tabela indicativa para a sua fixação médico-legal
}

\author{
Autor(es): $\quad$ Santos, J. Ferreira dos; Gouveia, A.; Carvalho, S.; Melo, R.; Gonçalves, \\ H.; Teixeira, M.
}

Publicado por: Imprensa da Universidade de Coimbra

URL

persistente:

URl:http://hdl.handle.net/10316.2/33139

DOI:

DOI:http://dx.doi.org/10.14195/1647-8630_19_3

Accessed : $\quad 26-A p r-2023$ 08:30:42

A navegação consulta e descarregamento dos títulos inseridos nas Bibliotecas Digitais UC Digitalis, UC Pombalina e UC Impactum, pressupõem a aceitação plena e sem reservas dos Termos e Condições de Uso destas Bibliotecas Digitais, disponíveis em https://digitalis.uc.pt/pt-pt/termos.

Conforme exposto nos referidos Termos e Condições de Uso, o descarregamento de títulos de acesso restrito requer uma licença válida de autorização devendo o utilizador aceder ao(s) documento(s) a partir de um endereço de IP da instituição detentora da supramencionada licença.

Ao utilizador é apenas permitido o descarregamento para uso pessoal, pelo que o emprego do(s) título(s) descarregado(s) para outro fim, designadamente comercial, carece de autorização do respetivo autor ou editor da obra.

Na medida em que todas as obras da UC Digitalis se encontram protegidas pelo Código do Direito de Autor e Direitos Conexos e demais legislação aplicável, toda a cópia, parcial ou total, deste documento, nos casos em que é legalmente admitida, deverá conter ou fazer-se acompanhar por este aviso.

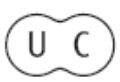




\title{
"Incapacidade total para 0 trabalho" - Proposta de Tabela Indicativa para a sua fixação médico-legal
}

\author{
J. Ferreira dos Santos ${ }^{1}$, A. Gouveia ${ }^{2}$, S. Carvalho ${ }^{3}$, R. Melo ${ }^{4}$, H. Gonçalves ${ }^{5}$, M. Teixeira ${ }^{6}$
}

\section{Considerações prévias}

A duração do período de incapacidade total para o trabalho (I.T.T.) revela-se como um factor fundamental na apreciação médico-legal da gravidade penal dos crimes contra a integridade física à luz do Código Penal vigente, tanto no nosso país como nos restantes países da União Europeia.

No âmbito da avaliação do Dano Corporal em sede de Direito Penal não existe nenhuma tabela baseada em critérios objectivos que possibilite aos Peritos Médicos uma avaliação concreta do período de incapacidade total para o trabalho (I.T.T.). Cumulativamente, observam-se, por vezes, assinaláveis disparidades, entre médicos, nas propostas de fixação da I.T.T. para idêntico tipo de lesão traumática, ou, mesmo, no próprio médico, que pode fixar uma I.T.T. muito diferente em duas vítimas tendo exactamente a/as mesma/s lesão/ ões traumática/s.

Com a finalidade de limitar e balizar estas variações inter e intra-pessoais, que podem ter consequências significativas no plano judicial, propomos o recurso a uma tabela indicativa para fixação médico-legal da I.T.T., aspecto que se afigura de grande utilidade para o Tribunal, ao qual caberá a deter-

\footnotetext{
Chefe de Serviço de Medicina Legal (Delegação do Sul do INML, IP).

Assistente Graduada de Medicina Legal (Delegação do Sul do INML, IP).

3 Assistente Graduado de Clínica Geral e Especialista de Medicina Legal (Delegação do Sul do INML, IP).

4 Interna do $1 .^{\circ}$ ano do Internato Complementar de Medicina Legal (Delegação do Sul do INML, IP).

5 Assistente Hospitalar de Medicina Dentária (Delegação do Sul do INML, IP).

6 Assistente Hospitalar de Ortopedia (Delegação do Sul do INML, IP).
} 
minação da medida da pena em função da gravidade das consequências do acto considerado criminoso.

Importa, no entanto e antes de mais, passar em revista alguns conceitos médico-legais básicos que norteiam toda esta temática, quanto mais não seja para que os leitores possam suprir dificuldades de interpretação, se possam integrar e identificar com a terminologia aqui utilizada, subsumível e directamente dependente do Código Penal vigente e com repercussões na prática médico-legal diária bem assim como, presumivelmente, também na administração da justiça.

\section{a) 0 conceito de "incapacidade total para o trabalho" (I.T.T.) em medicina legal}

Se bem que não exista nenhum texto legislativo que defina I.T.T., esta, no sentido penal do termo, pode definir-se como o período, exprimido em número de dias, durante o qual uma pessoa que sofreu uma lesão no corpo, na mente ou na saúde, devido a uma ofensa à integridade física, vai ter um estado de incapacidade.

Sequencialmente, este estado refere-se ao "trabalho pessoal" correspondendo à execução de actos básicos da vida diária tais como locomover-se, vestir-se, alimentar-se ou ter autonomia para a sua higiene pessoal p.e., e pode definir-se como uma perda de autonomia para gestos da vida quotidiana, não dizendo respeito ao trabalho, no sentido profissional do termo, mas às actividades usuais e pessoais da vítima.

Trata-se de uma incapacidade em sentido genérico que é comum à funcionalidade vulgar do indivíduo quer seja criança, velho, decrépito, estudante, reformado ou desempregado. Durante este período existe uma perturbação notável da capacidade total de uma pessoa mas tal não significa necessariamente uma interdição total das suas capacidades. É uma representação fotográfica do estado traumático de uma pessoa vítima de ofensa á integridade física e reflecte a amplitude do dano e a importância da violência sofrida condicionando, deste modo, o tratamento penal da infracção sofrida.

Prende-se com a impossibilidade para uma vítima de efectuar os actos da sua vida pessoal ou um trabalho corporal qualquer por oposição com a incapacidade para o trabalho profissional que concerne a incapacidade de realizar os actos da sua vida profissional.

A incapacidade total para o trabalho é, portanto, funcional; no sentido do Código Penal, o trabalho corresponde a todo o trabalho corporal, profissional ou não, doméstico ou outro, que uma pessoa pode ter de efectuar, não se tratando da amputação total de toda a capacidade, mas da amputação da capacidade total da vítima. 
Por outro lado, a incapacidade total para o trabalho, não exige que a incapacidade constatada seja absoluta e impossibilite o menor esforço muscular à vítima. Se a perda de autonomia fosse completa, toda a pessoa que comparecia a exame pericial não poderia estar em incapacidade total para o trabalho uma vez que estava apta a deslocar-se até ao médico; supõe, portanto, a existência de um traumatismo (dor ou "handicap", visível ou não) perturbando, de maneira anormal, os actos da vida corrente, sem, contudo, os interditar.

Não é necessário, "in fine”, estar num estado de incapacidade total, no sentido médico do termo, para estar em incapacidade total para o trabalho, no sentido penal do termo.

Para além disso, por "incapacidade total”, a jurisprudência tende a aceitar a existência duma certa actividade física da vítima, senão a única incapacidade total aceite seria aquela das pessoas em estado de coma ou que faleceram.

Quando uma vítima é hospitalizada ou imobilizada, a duração do internamento ou a duração da imobilização gessada constitui a duração mínima da I.T.T.

Fora destes casos a estimação da I.T.T. pode tornar-se mais complexa porque deve considerar não só as lesões traumáticas objectivas mas também a sua repercussão funcional e/ou psíquica.

A incapacidade total para o trabalho reflecte a violência sofrida e não a violência administrada, uma vez que, um mesmo tipo de ofensa, poderá ter consequências variáveis segundo as possibilidades de defesa da vítima.

Portanto, a duração da I.T.T., no sentido penal do termo, tem por fim determinar a gravidade das lesões traumáticas produzidas, exclusivamente no que concerne o trabalho genérico e indiferenciado, a fim de ser sancionado juridicamente o seu autor.

\section{b) 0 conceito de "lesão" em medicina legal}

Em medicina, "lesão" é toda a alteração funcional orgânica ou psíquica consecutiva a factores internos ou externos - expressão material da ofensa à integridade física.

O conceito médico-legal de "lesão", segundo a Organização Mundial de Saúde (O.M.S.), compreende "toda a alteração do equilíbrio bio-psico-social", que se ajusta à doutrina consignada no Código Penal em vigor.

Muito embora os artigos $143 .^{\circ}$ e $144 .^{\circ}$ do Código Penal vigente não empreguem a palavra "lesão", é evidente que as ofensas no corpo ou na saúde de outra pessoa são cometidas provocando lesões. 
No caso do emprego de qualquer arma de arremesso, arma de fogo ou outra, sem que tenham produzido qualquer das consequências previstas nos artigos $143 .^{\circ}$ e $144 .^{\circ}$, ou a simples ameaça com aquelas armas em disposição de ofender ou ainda p.e. uma injúria, constituem ofensas, em princípio, desprovidas de interesse médico-legal podendo, no entanto, reunir interesse judicial $^{7}$. Ou seja, para efeitos jurídico-penais há três aspectos que devem ser considerados, a saber, qualquer alteração da saúde ou do corpo de uma pessoa, com tradução material no seu corpo, e que essa alteração seja produzida por outrem.

Só têm interesse médico-legal as ofensas que se apresentam por meio de manifestações no corpo ou na saúde, sejam elas temporárias ou permanentes.

Do ponto de vista médico-legal, entendem-se por lesões, as equimoses, escoriações, feridas, fracturas, luxações e queimaduras p. e., mas também toda a alteração do corpo ou da saúde desde que deixe marcas detectáveis.

As ofensas à integridade física que interessam ao especialista de medicina legal, são as que provocam lesões ou deixam vestígios, assumindo-se a convicção que vestígio não é o que directamente produz a ofensa à integridade física - ex. ${ }^{\circ}$ contusão, ferida incisa, etc. -, mas o que, secundariamente, por assim dizer, dela resulta (crosta, cicatriz, etc. ...).

\section{c) 0 conceito de "doença" em Medicina Legal}

Diz respeito a "qualquer lesão no organismo que precisa de cura". "Três dias de curativo é o mesmo que três dias de doença", ou ainda, "toda a lesão no organismo que implica necessidade de prazo para a cura"10 ou consolidação.

Nas ciências médicas e linguagem comum, é um termo entendido como processo mórbido, alteração do estado de normalidade ou de equilíbrio dinâmico do organismo, ou ainda, e tão só, como a falta de saúde, podendo existir ofensa à integridade física sem que haja doença.

Relativamente à sua contagem, o tempo é contado em dias, tendo em conta a demora que a lesão produzida demandou para se curar (recuperação anatómica e funcional integral com restitutio ad integrum) ou para consolidar (recuperação anatómica e funcional parcial com sequelas que se mantém a partir de um determinado momento - data da consolidação).

\footnotetext{
7 Vide artigo 153. (ameaça), do Capítulo IV intitulado "Dos crimes contra a liberdade pessoal", do Código Penal Português, aprovado pelo Decreto-Lei n. ${ }^{\circ}$ 400/82, de 23 de Setembro e consignado igualmente na sua vigésima terceira alteração (Lei n. ${ }^{\circ}$ 59/2007, de 4 de Setembro).

8 Ac. Rel. Porto de 18.04.1912.

9 Ac. Rel. Porto de 16.04.1912.

10 Ac. Sup. Trib. Justiça, de 02.02.1917.
} 
A "doença" como consequência temporária de ofensa à integridade física ultrapassa, por vezes, a incapacidade total para o trabalho, podendo mesmo esta última nem existir.

\section{d) A atribuição, pelo especialista de medicina legal, de "dias de doença" e "dias de incapacidade total para o trabalho"}

O advento do Código Penal de 1982 fez desaparecer a obrigatoriedade do perito médico fazer constar, nos autos de exames periciais, o "tempo de doença" e de "incapacidade para o trabalho".

No entanto, "não obstante a ausência de tal obrigatoriedade, deve o médicolegista incluir sempre esta referência, não só porque uma norma de carácter geral o pressupõe [artigo $71^{\circ},{ }^{\circ}{ }^{\circ}$ 2, alínea a) do Código Penal], como também porque se reveste de grande utilidade para o trabalho do Juiz no momento da fixação da censura penal"11. A norma de carácter geral que se invoca consubstancia a determinação da medida da pena em função da gravidade das consequências do acto criminoso.

Cumpre aos Peritos Médicos, quando chamados pela justiça para se pronunciarem a respeito de ofensas à integridade física, emitir opinião sobre as consequências várias que dessas ofensas podem resultar, pelo que, nas suas conclusões, para além de outras de carácter doutrinário, deverão indicar sempre a duração da doença e da eventual incapacidade total para o trabalho genérico e indiferenciado que as lesões sofridas causaram, assumindo um valor indicativo de proporcionalidade entre a pena a aplicar dentro de uma certa margem penal e afigura-se de grande valor para os magistrados na altura da fixação da censura penal.

\section{Material e metodologia}

\section{II.1. Critérios básicos utilizados na construção da Tabela Indicativa da I.T.T.}

Esta Tabela Indicativa foi elaborada com a estreita colaboração do conjunto de médicos afectos à Unidade de Exames Médico-Legais (Penais) da Delegação do Sul do Instituto Nacional de Medicina Legal, I.P.

Foi criada em torno de dois eixos principais: o apelidado score lesional $(S L)$, que se obtém em função do tipo, do número e da dimensão máxima das

11 Henriques L., Santos S. (1986): “Código Penal de 1982 - referências doutrinárias, indicações legislativas, resenha jurisprudencial”, Rei dos Livros. 
lesões traumáticas observadas na vítima, ponderado pelo grau de perturbação funcional (PF) resultante da ofensa.

O score lesional considera, em primeiro lugar, o tipo mais grave das lesões constatadas (Lesão Major, a que corresponde a letra $\mathrm{M}$ ), segundo uma escala de gravidade que vai de 1 a 7 (Quadro I).

As lesões objectiváveis no exame clínico e, na sua falta, as descritas na documentação clínica disponível, foram incluídas; a rigidez osteo-articular também faz parte, mas não as dores isoladas.

A segunda variável considerada neste eixo corresponde ao número total de lesões traumáticas observadas $(\mathrm{N})$, dividido em classes de frequência, segundo uma escala de gravidade progressiva que vai de 0 (uma lesão), passando pelo 1 ( 2 a 5 lesões), pelo 2 (6 a 10 lesões) e terminando no 3 (mais de 10 lesões) (Quadro I).

A terceira e última variável deste eixo está relacionada com a dimensão da lesão major, medida no seu maior eixo (D), e é definida numa escala de gravidade igualmente progressiva e dividida em classes de frequência começando no 0 (menor que $1 \mathrm{~cm})$, passando pelo $1(1 \mathrm{a} 5 \mathrm{~cm})$, pelo $2(6 \mathrm{a}$ $10 \mathrm{~cm}$ ) e terminando no 3 (maior que $10 \mathrm{~cm}$ ) (Quadro I).

Um valor nulo é arbitrariamente atribuído quando uma lesão não é mensurável, como por exemplo, no caso de uma fractura, luxação ou de uma rigidez osteo-articular.

O score lesional (SL) é alcançado então pela soma aritmética dos valores parcelares absolutos respectivos obtidos no exame clínico da vítima a partir destas três escalas acabadas de descrever $(\mathrm{SL}=\mathrm{M}+\mathrm{N}+\mathrm{D})$ (Quadro I).

$\mathrm{O}$ segundo eixo da espinha dorsal desta tabela indicativa designa-se por grau de perturbação funcional (P.F.) e adquire uma função ponderadora intimamente relacionada com a definição de I.T.T. cujo objectivo assenta numa clara informação ao Magistrado sobre qual a repercussão funcional das lesões traumáticas sofridas clinicamente avaliada e é apreciado segundo uma escala qualitativa de gravidade progressiva englobando 4 grupos a que corresponde um valor absoluto de acordo com as seguintes correspondências:

* 0 (nula) - Sem perturbação funcional

* 1 (ligeira) - Dor ligeira e intermitente, permitindo uma actividade quase normal.

* 2 (moderada) - Dor na mobilidade activa, cedendo com o repouso, permitindo uma actividade limitada.

* 3 (grave) - Dores fortes na mobilidade activa e em repouso, impedindo toda e qualquer actividade.

Esta variável multiplica-se por 2 se as lesões atingem o membro superior correspondente à mão dominante.

$\mathrm{O}$ valor obtido do produto entre o score lesional (SL) e o grau de perturbação funcional (PF) é chamado grau de incapacidade - GI = SL X PF - (Quadro I). 
Quadro I. Critérios a considerar na construção da tabela indicativa para fixação médico-legal de I.T.T.

\begin{tabular}{|c|c|c|c|c|}
\hline & \multicolumn{2}{|c|}{ Lesão major } & $\begin{array}{l}\text { Número de } \\
\text { lesões }\end{array}$ & $\begin{array}{c}\text { Dimensão } \\
\text { da lesão major }\end{array}$ \\
\hline & \multicolumn{2}{|c|}{$M=1$ a 7} & $\mathbf{N}=\mathbf{0}$ a 3 & D $=0$ a 3 \\
\hline \multirow{11}{*}{$\begin{array}{l}\text { LESÕES } \\
\text { TRAUMÁTICAS }\end{array}$} & \multirow{11}{*}{\multicolumn{2}{|c|}{$\begin{aligned} & \text { Equimose }=1 \\
& \text { Queimadura } 1{ }^{\circ} \text { 'grau }=1 \\
& \text { Escoriação }=2 \\
& \text { Rigidez articular } / \\
& \text { Contractura muscular }=2 \\
& \text { Hematoma }=3 \\
& \text { Ferida }=4 \\
& \text { Queimadura }>\text {. }^{\circ} \text { grau }=4 \\
& \text { Entorse }=5 \\
& \text { Luxação }=6 \\
& \text { Fractura }=7\end{aligned}$}} & Uma lesão $=0$ & $<1 \mathrm{~cm}=0$ \\
\hline & & & 2 a 5 lesões $=1$ & 1 a $5 \mathrm{~cm}=1$ \\
\hline & & & 6 a 10 lesões $=2$ & 6 a $10 \mathrm{~cm}=2$ \\
\hline & & & $>10$ lesões $=3$ & $>10 \mathrm{~cm}=3$ \\
\hline & & & & \\
\hline & & & & \\
\hline & & & & \\
\hline & & & & \\
\hline & & & & \\
\hline & & & & \\
\hline & & & & \\
\hline SCORE LESIONAL (SL) & \multicolumn{4}{|c|}{$\mathbf{S L}=\mathbf{M}+\mathbf{N}+\mathbf{D}$} \\
\hline \multirow{4}{*}{$\begin{array}{l}\text { PERTURBAÇÃO } \\
\text { FUNCIONAL } \\
(\text { PF }) \rightarrow \mathbf{0} \text { a } 3 \\
\text { (X } 2 \text { se for no membro } \\
\text { superior dominante) }\end{array}$} & Nula $=0$ & \multicolumn{3}{|c|}{ Sem perturbação funcional. } \\
\hline & Ligeira = 1 & \multicolumn{3}{|c|}{$\begin{array}{l}\text { Dor ligeira e intermitente, permitindo uma acti- } \\
\text { vidade quase normal. }\end{array}$} \\
\hline & Moderada $=2$ & \multicolumn{3}{|c|}{$\begin{array}{l}\text { Dor na mobilidade activa, cedendo com o repouso, } \\
\text { permitindo uma actividade limitada. }\end{array}$} \\
\hline & Grave $=3$ & \multicolumn{3}{|c|}{$\begin{array}{l}\text { Dores fortes na mobilidade activa e em repouso, } \\
\text { impedindo toda e qualquer actividade. }\end{array}$} \\
\hline \multicolumn{2}{|c|}{ GRAU DE INCAPACIDADE (GI) } & \multicolumn{3}{|c|}{ GI $=\mathbf{S L} \times \mathbf{P F}$} \\
\hline
\end{tabular}

A partir de uma tabela de correspondência valorativa entre classes de frequência (Quadro II) ao grau de incapacidade obtido através das duas simples operações aritméticas atrás descritas, corresponde o período de incapacidade total para o trabalho em geral (em dias) que, no contexto da avaliação do dano corporal pós-traumático no âmbito do Direito Penal, pretende traduzir em dias o tempo de afectação da capacidade para o trabalho genérico baseado em critérios objectivos.

Quadro II. Tabela indicativa para fixação médico-legal de I.T.T. [correspondência valorativa entre o Grau de Incapacidade e o Período de Incapacidade Total (em dias)]

\begin{tabular}{|c|c|}
\hline $\begin{array}{c}\text { Grau de Incapacidade } \\
\text { (GI) }\end{array}$ & $\begin{array}{c}\text { Período de Incapacidade Total } \\
\text { (em dias) }\end{array}$ \\
\hline $0-4$ & $0-3$ dias \\
\hline $5-9$ & $4-6$ dias \\
\hline $10-19$ & $7-9$ dias \\
\hline $20-24$ & $10-12$ dias \\
\hline $25-29$ & $13-15$ dias \\
\hline$>=30$ & $>15$ dias \\
\hline
\end{tabular}


Caso se verifiquem lesões traumáticas mais graves que obriguem a internamento hospitalar e/ou a imobilização gessada p.e., ao período de incapacidade total para o trabalho calculado da forma já explicitada, deve ser adicionada a duração da imobilização e/ou de internamento em cada caso concreto (Quadro III - Fórmula da I.T.T.).

Quadro III

FÓRMULA DA I.T.T. = Período(s) de Incapacidade Total + Período(s) de Imobilização + (em dias) Período(s) de Internamento

\section{II.2. Avaliação da Tabela Indicativa para fixação médico-legal da I.T.T.}

Com base nestes elementos, a I.T.T. teórica foi calculada a partir de um quadro de correspondência (Quadro II) e também de acordo com a fórmula da I.T.T. quando necessário (Quadro III), tendo sido testada prospectivamente numa amostra aleatória de 120 vítimas de ofensa à integridade física observadas na Unidade de Exames Médico-Legais (Penais) da Delegação do Sul do Instituto Nacional de Medicina Legal, I.P.

As vítimas foram sucessivamente observadas por um Perito Médico avaliando livre e classicamente a I.T.T. e depois por outro médico que procedeu à avaliação da I.T.T. unicamente de acordo com os critérios da Tabela actualmente proposta por forma a poder ser comparada a sua duração fixada livre e classicamente, com a fixada estritamente segundo os critérios objectivos da nova tabela.

Para cada caso, a idade, o sexo, as queixas da vítima, o local da ofensa, bem assim como a data e hora da ocorrência, o tipo de ofensa sofrida, tipo de lesão traumática major, número total e dimensão máxima das lesões traumáticas produzidas, assim como o grau de perturbação funcional resultante foram as variáveis consideradas importantes para este estudo preliminar.

Em todos os casos, a I.T.T. clássica foi comparada com a I.T.T. teórica da tabela. A presença de discordâncias entre os dois valores foi assinalada e referenciados os motivos de cada uma delas.

\section{Resultados}

$92,5 \%(\mathrm{n}=111)$ das vítimas foram observadas no âmbito de ofensas produzidas por outrem e as restantes $7,5 \%(\mathrm{n}=9)$ no âmbito de sinistralidade rodoviária.

A idade média da amostra populacional em apreço situou-se nos 39 anos (idade mínima 11 anos, idade máxima 86 anos), a mediana em 34 e a moda em 27 (Desvio Padrão=17,6). O ratio Homem/Mulher foi, curiosamente, de 1 
(60/60), constatando-se uma ligeira prevalência do sexo masculino sobretudo na década dos 20-29 anos (fig. 1).

Constataram-se lesões traumáticas variadas (fig. 2), entre as quais o hematoma (26\%), a ferida ( $23 \%)$, a escoriação ( $23 \%)$ e a equimose (18 $\%)$, sendo as lesões mais graves (10\%), a fractura (9\%) e a luxação (1\%).

Metade das vítimas sofreram entre 2 a 5 lesões traumáticas, 32,5\% uma única lesão, $12,5 \%$ entre 6 e 10 lesões e só $5 \%$ das vítimas apresentava mais de 10 lesões traumáticas (fig. 3).
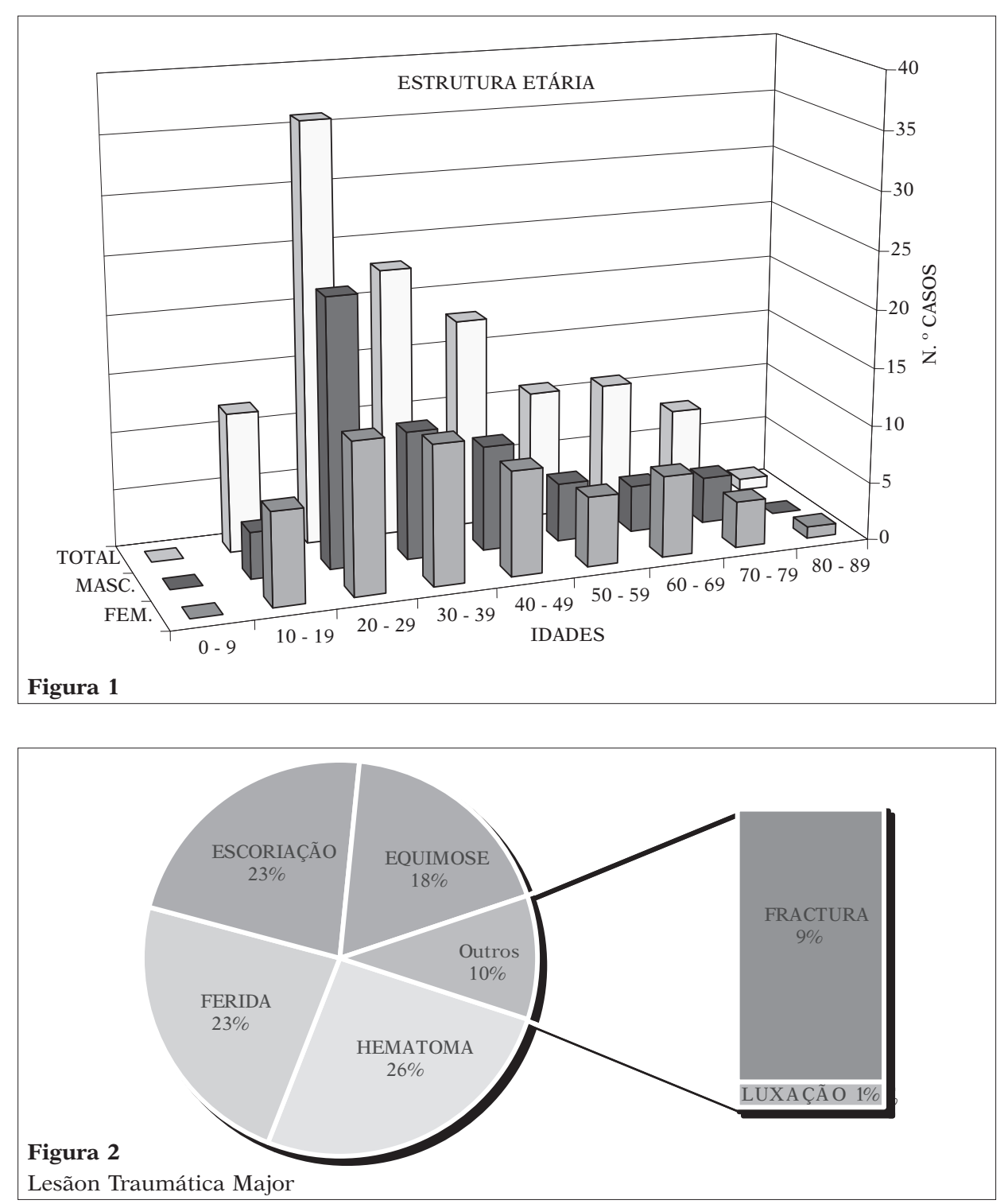


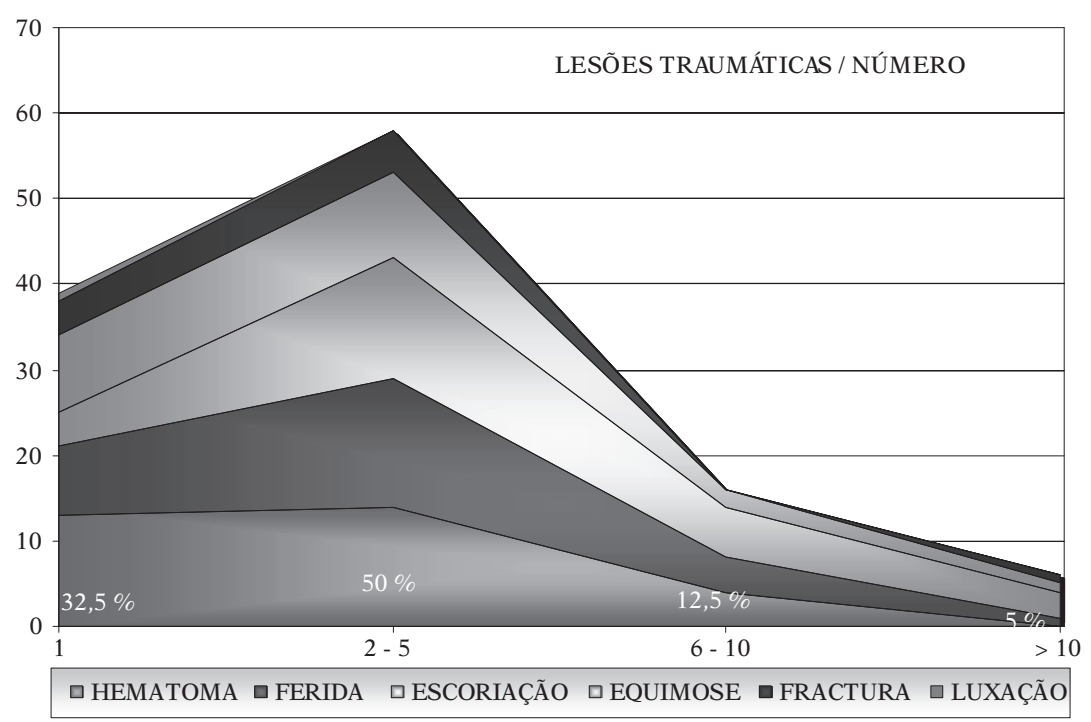

Figura 3

Em 66,7\% ( $\mathrm{n}=80)$ dos casos a dimensão máxima da lesão major, medida no seu eixo maior, foi quantificada entre 1 e $5 \mathrm{~cm}$, em $16,7 \%(\mathrm{n}=20)$ a sua dimensão situou-se entre 6 e $10 \mathrm{~cm}$ e em 13,3\% $(\mathrm{n}=16)$ foi menor do que $1 \mathrm{~cm}$ (fig. 4). Em muito poucos casos, esta dimensão foi superior a $10 \mathrm{~cm}$ $(3,3 \% ; n=4)$.

Constatou-se um coeficiente de correlação forte $(r=0,84)$ com a perturbação funcional resultante da ofensa, tendo, em $71 \%(\mathrm{n}=85)$ dos casos, o grau de perturbação funcional sido ligeiro, moderado em $18 \%(\mathrm{n}=22)$ dos casos e grave em $11 \%(\mathrm{n}=13)$ desta casuística (fig. 5).

A I.T.T. média, fixada livre e classicamente pelo médico, foi de 5 dias para os casos de ofensas produzidas por outrem, e de 30 dias nos casos de sinistros rodoviários.

A I.T.T. avaliada segundo a tabela indicativa (D.P. $=3,42$ ), nos casos de ofensas produzidas por outrem (O.P.O.), ficou compreendida entre 4 e 6 dias em $43 \%$ dos casos e entre 1 e 3 dias em 35,8 \% dos casos (média = 7 dias) e, nos casos de sinistros rodoviários (S.R.), a média foi de 29 dias (fig. 6), constatando-se um coeficiente de correlação forte e muito forte, respectivamente com a gravidade lesional sofrida $(\mathrm{r}=0,79)$ - fig. 7 , e com a I.T.T resultante $(\mathrm{r}=0,97)-$ fig. 6 . 
79 "Incapacidade total para o trabalho"

Figura 4

Dimensão máxima da lesão Major
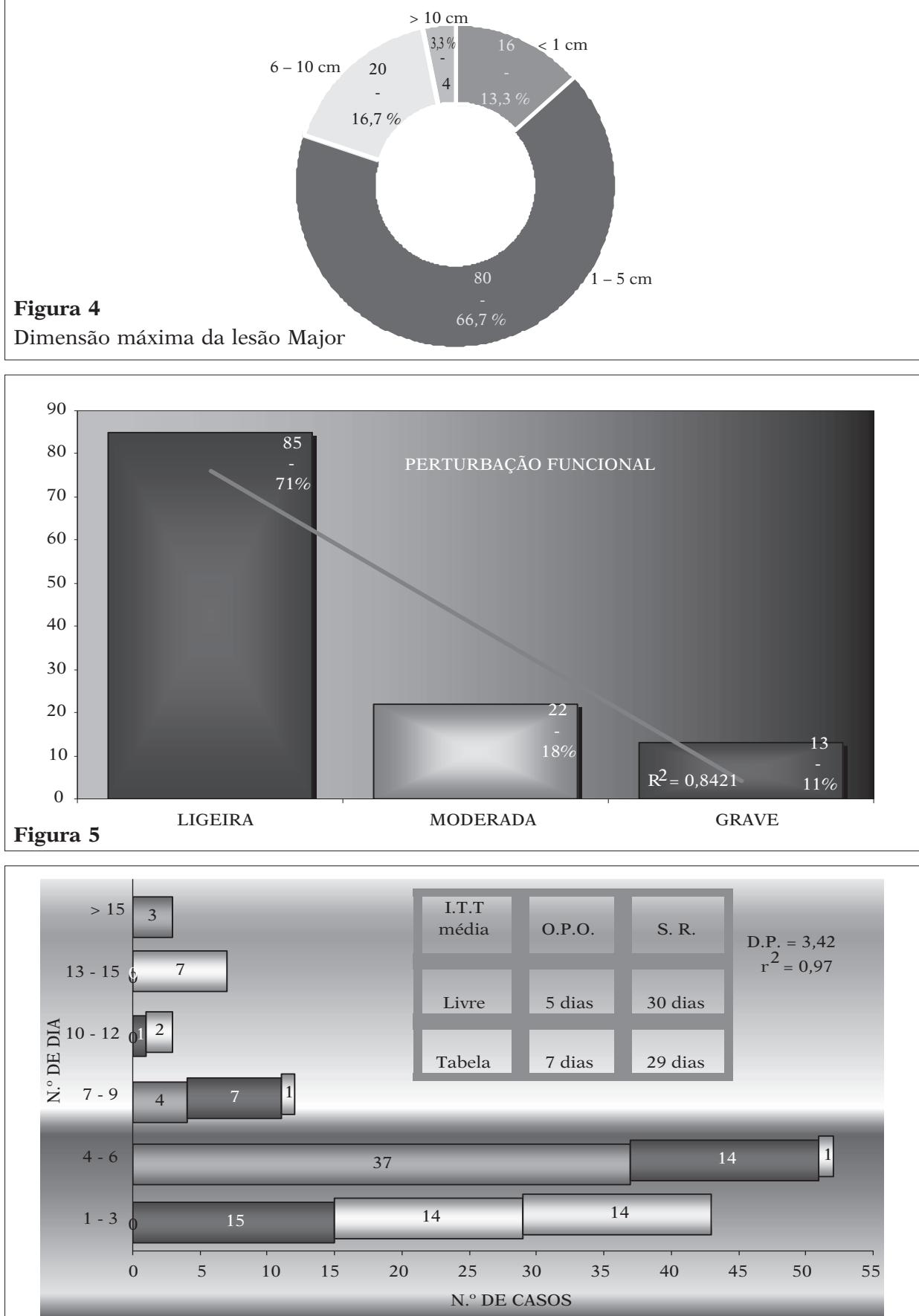

Figura 6

Períodos de Incapacidade Total para o Trabalho Genérico e Indiferenciado 


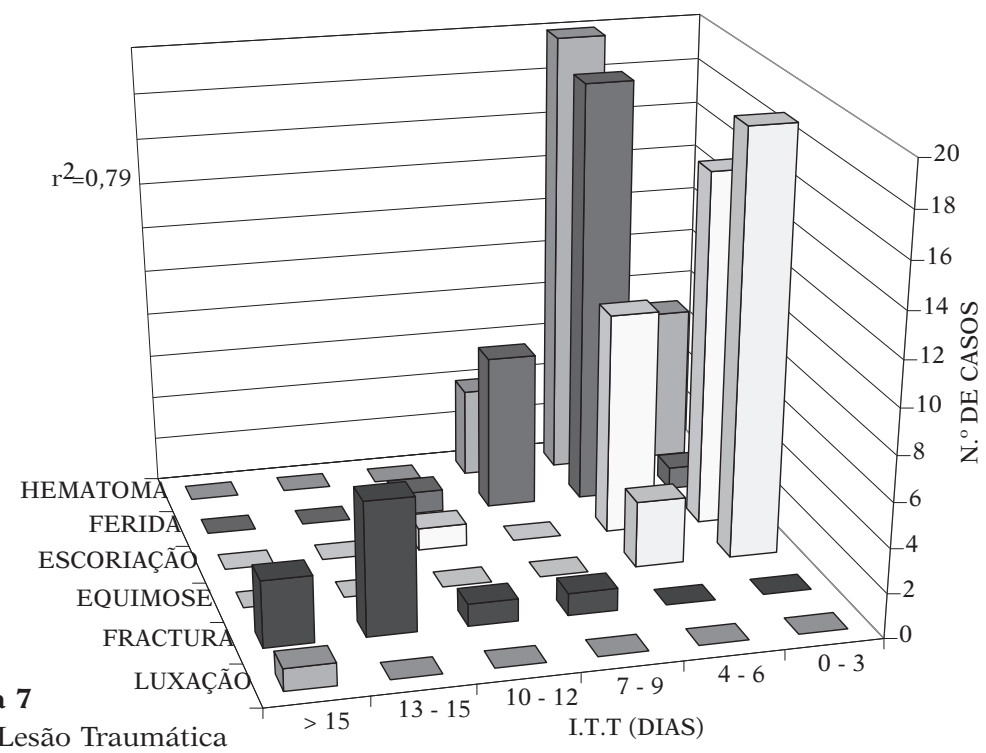

Duas realidades distintas se observaram quando estudada a demora média entre a ofensa e a realização do exame pericial, nos casos de ofensas produzidas por outrem e depois nos casos de sinistros rodoviários.

Oitenta e cinco por cento dos casos de ofensa à integridade física produzida por outrem $(\mathrm{n}=102)$ foram objecto de exame pericial nos primeiros 10 dias após a ofensa $(\min .=0$, máx. $=1273)$, sendo a moda de 2 , a mediana de 4 e a média de 35 dias (fig. 8).

Dos 9 casos estudados no caso dos sinistros rodoviários, excepção feita a um deles que foi observado 2 dias após o sinistro, todos os outros exames periciais sucederam longo tempo após a ofensa $(\min =2$, máx. $=189)$, sendo a moda de 2, a mediana de 98 e a média de 90 dias (fig. 9).

Os raros factores de discordância entre estes dois métodos estiveram relacionados com casos de lesões traumáticas específicas que necessitaram avaliação pericial complementar por especialidades médico-cirúrgicas (otorrinolaringologia, estomatologia, oftalmologia, p.e.), casos com eventual necessidade de apreciação das repercussões psicológicas temporárias das ofensas à integridade física ou ainda 1 caso que se revestiu de dificuldades acrescidas em virtude do exame pericial ter sucedido muito tempo depois da ofensa [1273 dias ó 3,5 anos] e já com completo desaparecimento das lesões traumáticas imputáveis aquela. 


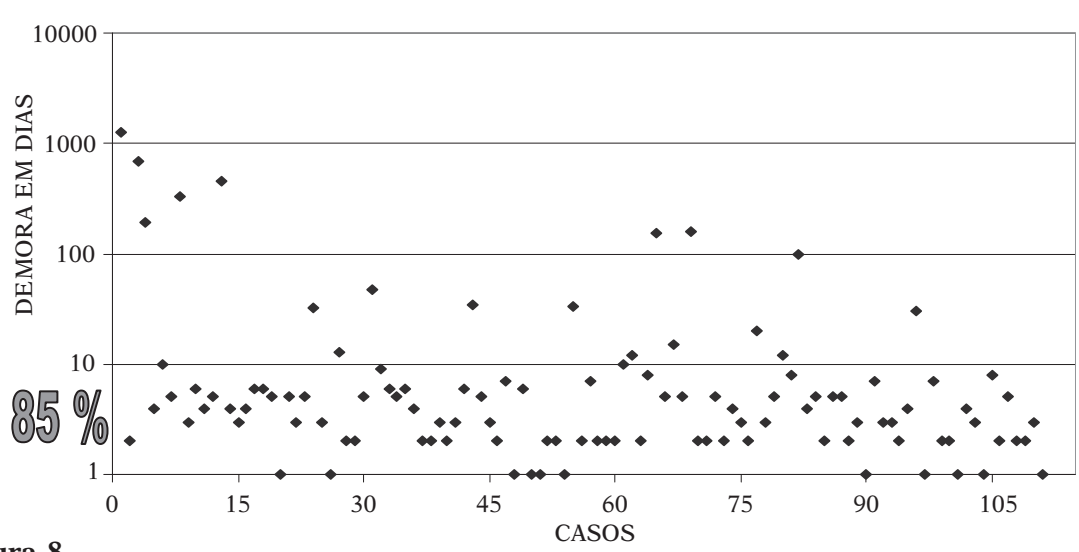

Figura 8

Demora média entre ofensa e exame pericial (ofensas prouzidas por outrem)

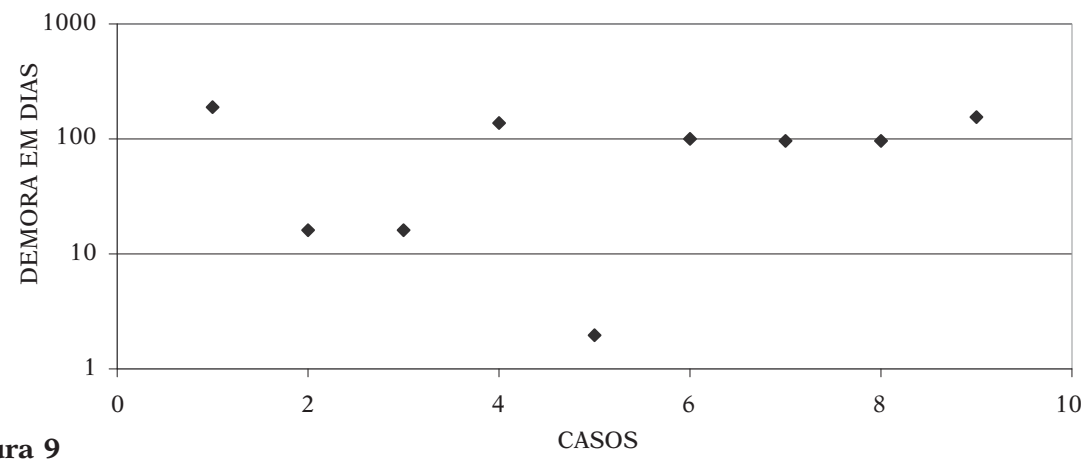

Figura 9

CASOS

Demora média entre ofensa e exame pericial (sinistralidade rodoviária)

\section{Discussão}

No domínio dos crimes contra as pessoas e concretamente contra a integridade física, a legislação penal portuguesa vigente distingue ofensas à integridade física simples e graves e pune os autores dos actos de violência em função das suas consequências.

Quando as ofensas são exercidas perante circunstâncias agravantes, as penas são majoradas e as disposições actuais do Código Penal prevêem mais de uma dezena de circunstâncias agravantes que concernem, quer a qualidade da vítima, a qualidade do agente, ou ainda as circunstâncias que estiveram na génese daquela ou envolveram especial censurabilidade ou perversidade.

Muito embora os artigos $143 .^{\circ}$ e $144 .^{\circ}$ do Código Penal vigente, não empreguem a palavra lesão, é evidente que as ofensas no corpo ou na saúde de outra pessoa, são cometidas provocando lesões, havendo, para efeitos 
jurídico-penais, três aspectos que devem ser considerados, a saber, qualquer alteração da saúde ou do corpo de uma pessoa, com tradução material no seu corpo, e que essa alteração seja produzida por outrem.

Como já explanado se é facto que, pelo Código Penal vigente, o médico não será obrigado a consignar no seu relatório, o "tempo de doença" e de "incapacidade para o trabalho" que as lesões sofridas demandaram para curar (excepção feita aos casos subsumíveis do artigo 148. ${ }^{012}$ ) ou consolidar, não é menos certo que uma tal indicação se reveste de extrema utilidade para o Tribunal, ao qual, conforme norma de carácter geral (alínea a), n. ${ }^{\circ}$ 2, do artigo $71 .^{\circ}$ ) que consubstancia a determinação da medida da pena em função da gravidade das consequências do acto criminoso, caberá o aproveitamento da sua extensão para efeitos jurídico-penais.

Salvo melhor entendimento, clássica e doutrinariamente, neste contexto e neste âmbito de avaliação do dano, o Perito Médico quando chamado pela justiça para se pronunciar a respeito de ofensas à integridade física, na sua avaliação - para além de outras conclusões de carácter doutrinário -, deve pronunciar-se, na generalidade, sobre duas consequências da ofensa sofrida:

a) O tempo de doença;

b) O período de incapacidade total para o trabalho genérico e indiferenciado.

Actualmente, pelo facto da ausência de definição de I.T.T. por um texto legislativo, esta é ainda por vezes confundida com a incapacidade para realizar os actos da vida profissional e por isso com a incapacidade para o trabalho profissional.

Para além disso, não é raro ver relatórios de avaliação do dano corporal no âmbito do Direito Penal não descrevendo nenhumas lesões ou lesões sem nenhumas repercussões funcionais, ambos com propostas de fixação de I.T.T. de mais de três dias. Cumulativamente, observam-se, por vezes, assinaláveis disparidades, entre médicos, nas propostas de fixação da I.T.T. para idêntico tipo de lesão traumática, ou, mesmo, no próprio médico, que pode fixar uma I.T.T. muito diferente em duas vítimas tendo exactamente a/s mesma/s lesão/ ões traumática/s.

Em virtude deste tipo de lapsos poder ter consequências significativas no plano judicial criando efectivas dificuldades ao Tribunal, a quem cabe a determinação da medida da pena em função da gravidade das consequências do acto considerado criminoso, os autores criaram a tabela indicativa acabada de apresentar baseada em critérios objectivos com intuito de limitar e balizar pelo menos aquelas variações inter e intra-pessoais, afigurando-se

12 Ofensa à integridade física por negligência. 
ter potencialidades para ser um utensílio a encarar na prática médico-legal corrente e que se propõe ajudar tanto Médicos como Magistrados neste propósito comum de avaliação do dano pós-traumático fundado em critérios similares e surge na senda das já existentes tabelas funcionais utilizadas na avaliação da incapacidade permanente no âmbito do Direito Civil.

Permitimo-nos elencar algumas vantagens que o uso desta tabela destacou através do nosso estudo.

Em primeiro lugar, centra a fixação da I.T.T. na avaliação ponderadora da perturbação funcional (P.F.) associada à/s lesão/ões sofridas, numa clara proporcionalidade com a definição de I.T.T. Sequencialmente, a todas as lesões traumáticas desprovidas de perturbação funcional, corresponde uma I.T.T. de valor nulo quando a tabela é aplicada.

Em segundo lugar, dá a conhecer, ao não médico e concretamente ao Magistrado, os elementos objectivos e a metodologia em que o Perito Médico se baseou para formular a sua proposta de I.T.T. em cada caso concreto, conferindo legitimidade, em particular ao Juiz, para opinar quanto à duração da I.T.T. proposta pelo Perito Médico no relatório pericial, admitindo por conseguinte a possibilidade daquela poder ser discutida ou mesmo contestada em caso de discordância atendível.

Paralelamente, esta tabela deixa uma grande liberdade ao Perito Médico para a sua apreciação clínica qualitativa da perturbação funcional, obrigandoo consecutivamente a ser preciso quanto ao tipo, número e dimensão das lesões traumáticas constatadas, devendo o grau de perturbação funcional ser sistematicamente precisado em todos os relatórios periciais.

Em terceiro lugar, assinala-se a contribuição clara para limitar e balizar as variações inter e intra-pessoais da avaliação clássica da I.T.T. e das disparidades que neste último caso se verificam, sendo possível com base numa avaliação puramente objectiva que a proposta de fixação médico-legal da I.T.T. seja nivelada para idêntico tipo de lesão traumática, variando sim, de acordo com o eventual compromisso funcional acessório.

Finalmente, trata-se de uma tabela que só tem valor indicativo e cuja utilização se ancora na potencial ajuda que veicula ao Perito Médico numa avaliação pericial sustentada nos elementos objectivos encontrados em cada caso concreto e que se pretende o possa auxiliar na sua proposta de fixação médico-legal da I.T.T., manifestando-se particularmente eficaz na presença de lesões traumáticas recentes, na ausência de qualquer assistência clínica ou na ausência de qualquer documentação clínica correlacionada.

Todavia, esta tabela indicativa proposta no nosso estudo não é nem nunca poderia ser perfeita, apresenta algumas insuficiências susceptíveis de serem colmatadas progressivamente por alterações introduzidas pela experiência dos Peritos que a utilizem com regularidade. 
Surgiram, durante este estudo preliminar, algumas dificuldades no seu uso e que se prenderam:

a) Com a superveniência de lesões traumáticas específicas já evocadas (ORL, dentárias, oftalmológicas, etc. ...) uma vez que a sua potencial valorização fica dependente da realização de um exame pericial complementar, adstrito à especialidade respectiva, antes de ser fixada a eventual I.T.T.

b) Com a valorização médico-legal das repercussões psicológicas sequenciais a uma ofensa à integridade física.

Esta valorização não é consignada, em concreto, na tabela em avaliação. Só o será se esta sintomatologia tiver a relevância necessária para poder ser integrada num valor positivo (de 1 a 3) do apelidado grau de perturbação funcional (P.F.) contribuindo portanto, por si só, ou em conjunto com outras lesões traumáticas, para um determinado Grau de Incapacidade (G.I.) conferindo-lhe um correspondente período de incapacidade total para o trabalho em conformidade com a sua gravidade (Quadro II).

Relativamente a esta sintomatologia (insónias, pesadelos, queixas ango-depressivas, pavor de sair de casa, etc. ....), é plena convicção dos autores que a sua constatação pós-traumática recente se mostra difícil de avaliar, requerendo, por norma, uma reavaliação pericial alguns dias mais tarde com vista a estimar uma eventual I.T.T. no sentido penal do termo ou a eventual necessidade de ulterior avaliação psiquiátrica.

c) Deparámo-nos com dificuldades acrescidas num caso em que o exame pericial só veio a ter lugar muito tempo depois da produção da ofensa à integridade física [1273 dias ó 3,5 anos] e já com completo desaparecimento das lesões traumáticas imputáveis aquela.

Claro está que, nestes casos, o Perito Médico fica completamente dependente da informação clínica possível de reunir e que deve incluir uma descrição tão fiel quanto possível das lesões traumáticas iniciais e da situação clínica que, por via das mesmas, foi criada à vítima, bem assim como incluir toda a evolução cronológica destas. Na posse destes fundamentais elementos, poderá então o Perito, por via indirecta, aplicar os dados parcelares da tabela indicativa que consideramos, com a finalidade predefinida.

Sucede que, infelizmente, nem sempre estes requisitos fundamentais são cumpridos e, ou as lesões traumáticas não estão bem identificadas, ou não foi feita a sua descrição ou ainda, os elementos clínicos disponibilizados estão incompletos relativamente à evolução clínica, criando situações de difícil diagnóstico e que implicam condutas específicas a avaliar caso a caso. 
Com a utilização regular desta Tabela é provável que outras discordâncias com a realidade clínica, para além das assinaladas, possam impor alguns ajustamentos ou mesmo correcções que iremos, numa segunda fase, tentar descortinar através da sua análise numa amostra mais expressiva no panorama médico-legal português.

Apesar de algumas insuficiências assinaladas, é inegável que as inúmeras vantagens do uso desta tabela de valor indicativo na fixação médico-legal do período de I.T.T. carreadas por este estudo preliminar, constituem resultados animadores para que possa ser objecto de uma conferência de consenso e deva constituir uma base de reflexão tendente a ajudar tanto Médicos como Magistrados numa avaliação predominantemente objectiva das consequências das ofensas à integridade física e no aproveitamento da sua extensão para efeitos jurídico-penais.

\section{Conclusões}

1. Através deste estudo preliminar e estribados nos animadores resultados obtidos, aos autores afigura-se que a introdução duma tabela indicativa, como a proposta, na temática da avaliação médico-legal da I.T.T., deva constituir uma base de reflexão que se propõe ajudar, tanto médicos como magistrados, numa avaliação mais objectiva das consequências das ofensas à integridade física e no aproveitamento da sua extensão para efeitos jurídico-penais.

2. A utilização desta tabela de valor indicativo não deve jamais ser encarada como uma condicionante que prive o Perito Médico da apreciação clínica pessoal de cada vítima, mas sim como uma ferramenta útil, simples, reprodutível, transparente e de fácil e rápida utilização na avaliação pericial do Dano Corporal em Clínica Forense (fig. 10) e, concretamente, na fixação prática diária da denominada incapacidade total para o trabalho genérico e indiferenciado.

3. Pontificam indicadores que apontam para a sua particular eficácia na presença de lesões traumáticas recentes, na ausência de qualquer assistência clínica ou na ausência de qualquer documentação clínica correlacionada. 


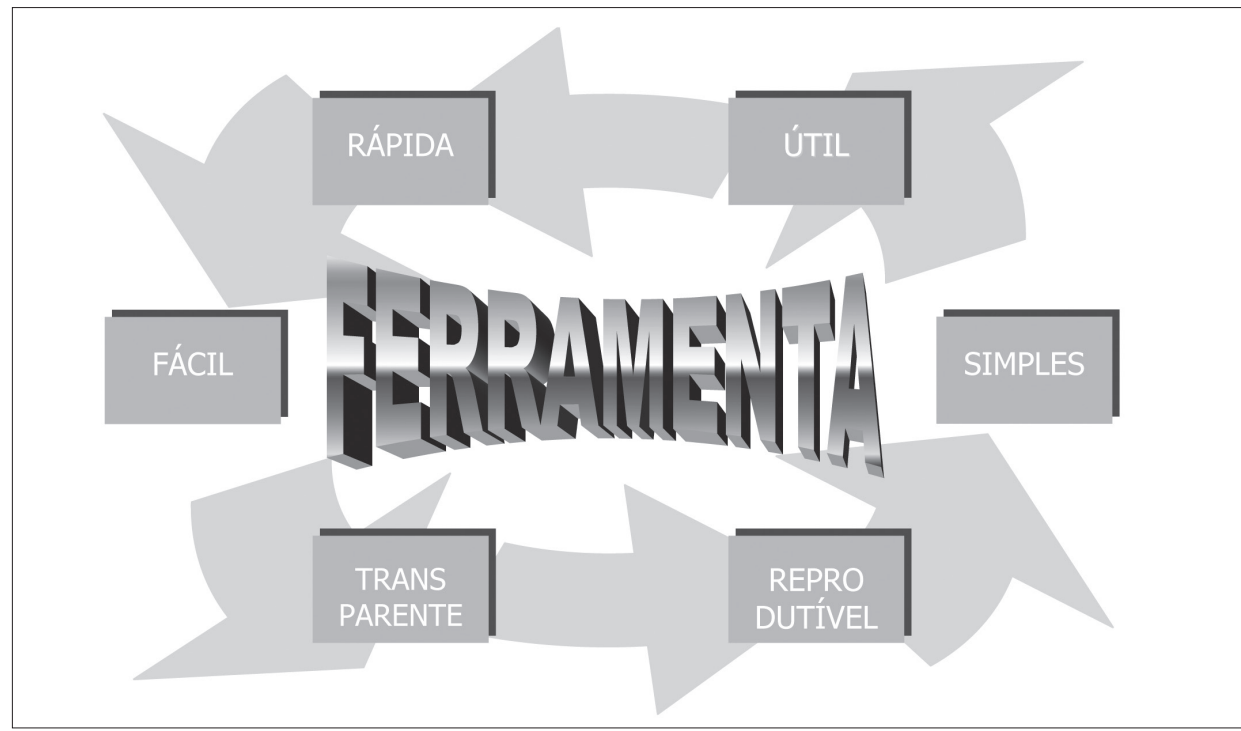

\section{Bibliografia}

Brémond G, Daupleix D. Évaluation des dommages dans les traumatismes du sujet âgé. Rev. Fr. Dommage Corp. 2005; 3: 65-73.

Chariot P, Bourokba N. L'incapacité totale de travail, le médecin et la victime. Med. Leg. Soc. 2002; 5: 26-27.

Clarot F, Papin F, Proust B. Difficultés concernant la determination de l'incapacité totale de travail. Med. Leg. Soc. 2002; 5: 19-20.

Costa Santos J, Mendes Dias CJ. As ofensas corporais e o código penal. Da letra da lei à prática médico-legal. Jornal do Médico. 1987; 2239: 423-430.

Demont L. La notion d'incapacité totale de travail en droit positif. Med. Leg. Soc. 2002; 5: 5-10.

Diamant-Berger O, Zillhardt P, Benayoun, S, et al. L'incapacité totale de travail - L'ITT + $\mathrm{P}$ - Un terme donnant lieu à tous les contresens. Médecine \& Droit. 1993; 3: 69-70.

Doriat F, Peton P, Coudane H, Py, B, et al. L'incapacité totale de travail en matière pénale: pour une approche médico-... légale. Médecine \& Droit. 2004; 27-30.

Durigon M. Pratique médico-légale. Paris: Masson; 1999. p. 153-5.

Grandmaison GL, Durigon M. Incapacité totale de travail: proposition d'un barème indicatif. La Revue du Praticien. 2006; 718: 111-113.

Gromb S, Dost C. L'état d'incapacité temporaire totale et la qualification des violences. Méd \& Droit. 2001; 48: 21-23.

Herpin D. L'avocat face à l'incapacité totale de travail. Med. Leg. Soc. 2002; 5: 15-16.

Jousset N, Gaudin A, Gaches T, et al. Incapacité totale de travail et accident de la voie publique. Journal de Médecine Légale Droit Médical. 2005; 48: 83-87.

Lasseuguette K, Grandmaison GL, Bourokba N, et al. Intérêts et limites d'un barème indicatif de l'Incapacité Totale de Travail (ITT). Journal de Médecine Légale Droit Médical. 2004; 47: 123-128. 
Leturmy L. Justice pénale et urgences médico-légales. Dossier urgence sociale et urgence sanitaire. 2007; 3: 436-445.

Lopez G. Prise en compte du retentissement psychologique dans l'évaluation de l'incapacité totale de travail. Med. Leg. Soc. 2002; 5: 93-95.

Maia Gonçalves M. Código Penal Portugués. Anotado e Comentado e Legislação Complementar. 2. ${ }^{a}$ ed. Coimbra: Almedina; 1984.

Oliveira Sá F. As ofensas corporais e o Novo Código Penal - Primeiros comentários médicolegais. O Médico. 1982; 1618: 201-13.

Pinto da Costa J. Ofensas Corporais - Introdução ao seu estudo médico-legal. O Médico 1983; 1648: 422-40.

Plu I, Toubin E, Purssell-François I. Impact des variations de prise en charge médicale sur la determination des Incapacités Totales de Travail: une question d'équité. Journal de Médecine Légale Droit Médical. 2006; 49: 204-8.

Riomet N. Incapacité totale de travail vue par le parquet. Med. Leg. Soc. 2002; 5: 11-14.

Sattonnet P. L'incapacité totale de travail en pratique quotidienne. Med. Leg. Soc. 2002; 5: $17-18$.

Silva F. Direito Penal Especial. Crimes contra as Pessoas. 2. ${ }^{\mathrm{a}}$ ed. Lisboa: Quid Juris Editora; 2008.

Resumo: Incapacidade total para o trabalho - Proposta de tabela indicativa para sua fixação médico-legal

No âmbito da avaliação do Dano Corporal em sede de Direito Penal não existe nenhuma tabela baseada em critérios objectivos que possibilite aos Peritos Médicos uma avaliação concreta do período de incapacidade total para o trabalho (ITT). Cumulativamente, observam-se, por vezes, assinaláveis disparidades, entre médicos, nas propostas de fixação da ITT para idêntico tipo de lesão traumática, ou, mesmo, no próprio médico, que pode fixar uma ITT muito diferente em duas vítimas tendo exactamente a/as mesma/s lesão/ões traumática/s.

Com a finalidade de limitar e balizar estas variações inter e intra-pessoais, que podem ter consequências significativas no plano judicial, propomos o recurso a uma tabela indicativa para fixação médico-legal da ITT, aspecto que se afigura de grande utilidade para o Tribunal, ao qual caberá a determinação da medida da pena em função da gravidade das consequências do acto considerado criminoso.

Através deste estudo e estribados nos animadores resultados obtidos, aos autores afigura-se que a introdução duma tabela indicativa, como a proposta, na temática da avaliação médicolegal da ITT, deva constituir uma base de reflexão que se propõe ajudar, tanto médicos como magistrados, numa avaliação mais objectiva das consequências das ofensas à integridade física e no aproveitamento da sua extensão para efeitos jurídico-penais, não devendo jamais ser encarada como uma condicionante que prive o Perito Médico da apreciação clínica pessoal de cada vítima, mas sim como uma ferramenta útil, simples, reprodutível, transparente e de fácil e rápida utilização na avaliação pericial do Dano Corporal em Clínica Forense e, concretamente, na fixação prática diária da ITT.

Palavras-chave: Tabela; ITT; exame pericial. 
Summary: Evaluation of total disability for work - A proposed scale in clinical forensic expertise In the evaluation of body damage under the Portuguese Penal Code there is no parametric reference based on the objective criteria that can enable the Medical Expert's real assessment of the total disability for work (TDW). Cumulatively, there are at times notable differences between doctors for fixing the TDW for the same type of traumatic injury, or at other times the same doctor can set a different TDW in two cases having the same traumatic lesion/s. In order to limit and mark out these intra and inter-individual variations which may have a significant impact on judicial basis, it is proposed the use of an indicative scale to establish the TDW, which should be valuable in the judicial decision.

The chart is the result of a study done by the authors on their daily forensic expertise and proposed as a guide in the daily practice, and it should not be seen as a handicap which deprives the expert, but as a useful tool, clear and simple to manage in taking decisions.

Key-words: Total disability scale; TDW; forensic expertise.

Résumé: Incapacité totale de travail - Proposition d’un barème indicatif pour sa fixation médicolégale.

Il n'existe actuellement aucune échelle d'évaluation objective de l'incapacité totale de travail (ITT) à la disposition des médecins amenés à rédiger des expertises médicales. On observe ainsi de grandes disparités entre médecins dans la fixation médico-légale des ITT pour un même type de lésion traumatique, voire parfois pour un même médecin.

Afin de limiter ces variations inter et intra-individuelles que peuvent avoir des conséquences importantes sur le plan judiciaire, nous proposons un barème indicatif pour la fixation médico-légale de l'ITT.

Les résultats obtenus avec notre étude ont montré que l'introduction de ce barème peut constituer une base de réflexion aidant médecins et magistrats et doit être jugée comme un outil simple, reproductible, facile et de rapide utilisation dans la recherche d'une estimation aussi objective que possible de l'ITT dans la pratique medico-judiciaire, et non comme un carcan privant le médecin légiste de son appréciation clinique personnelle de chaque victime.

Mots-clés: Barème; ITT; expertise médicale.

Pedido de separatas:

J.L. FERREIRA DOS SANTOS

gabsantos@hotmail.com 